Endocrinol. Japon. 1985, 32 (1), 135-140

\title{
Salivary Testosterone Concentration and Testicular Volume in Male Infants
}

\author{
Hiromasa CHO, Kazunori SANAYAMA, Nozomu SASAKI \\ AND HIRONORI NAKAJIMA \\ Department of Pediatrics, Chiba University School of Medicine, \\ 1-8-1 Inohana, Chiba 280
}

\begin{abstract}
In order to investigate the changes in testicular volumes (TV) and salivary testosterone concentrations (ST) in normal male infants aged from birth to one year, TV in 158 and ST in 61 infants were measured cross-sectionally during this period. ST of normal male adolescents in Tanner's pubic hair stage from P2 to P5 $(n=20)$ were also measured as the control. To clarify the relationship between remarkable height increase and testosterone $(\mathrm{T})$ during early male infancy, longitudinal follow-up of 10 male infants (4 from birth to 4 months, 6 from birth to 7 months) were also carried out by simultaneous measurement of ST and crown-heel length. Maximum TV (ml) was observed at 1-4 months $(1.7 \pm 0.6)$ (mean $\pm \mathrm{SD})$ and was significantly higher than the values at birth $(0.5 \pm$ $0.1, \mathrm{P}<0.01)$ and at $6-12$ months of age $(1.4 \pm 0.4, \mathrm{P}<0.01)$. Maximum ST (ng/dl) was also observed at 1-4 months, with the mean value being $3.4 \pm 1.5$, which was significantly higher than $1.9 \pm 0.8$ at $6-12$ months $(\mathrm{P}<0.01)$. The ST at four month was not significantly different from that at Tanner's pubic hair stage P2. The longitudinal study showed that the rise in ST was concomitant with the maximum increase in crown-heel length at 1-4 months. The fluctuations in ST and height increase were also apparently synchronous during the first year.
\end{abstract}

During early infancy the presence of signs of puberty, such as engorgement of the breasts (Mckiernan and Hull, 1981), acne (Esterly and Soloman, 1977) and testicular enlargement (Zilka and Laron, 1969; Cassorla et al., 1981) has been demonstrated.

The finding of high serum LH values (Forest et al., 1974; Winter et al., 1975; Hammon et al., 1978), an increased response of LH to LHRH (Garnier et al., 1974), parallel chages in serum $\mathrm{LH}$ and $\mathrm{T}$ (Gendrel et al., 1980), and a pulsatile secrection of

Received October 19, 1984 gonadotropine (Waldhauser et al., 1981) in early infancy indicate a postnatal activation of the pituitary-gonadotropin axis, resembling the hormonal environment of puberty. These phenomena found in early infancy are termed the so-called genital crisis by Job (1981). The pubertal growth spurt is considered to be mainly caused by sex hormone (Blizzard et al., 1974), while the factors responsible for the $25 \mathrm{~cm}$ height increase during the first year of life, especially the $16-17 \mathrm{~cm}$ increase in the first six months have remained unclear.

An increase in testosterone estradiol 
binding globulin (TeBG) in this period has been described (Chaussain et al., 1978), suggesting that the increase in total $\mathrm{T}$ concentration during this period could be due to the increase in $\mathrm{T}$ binding protein.

Recently, Baxendale et al. (1982) and Wang et al. (1981) demonstrated that TeBG was not identified in the saliva of men and that the salivary testosterone (ST) concentration had a good correlation with the serum free $\mathrm{T}$ level.

This report showed the changes in ST and TV and tried to demonstrate the relationship between height increase and the ST level during the early infancy of males.

\section{Materials and Methods}

The TV of 158 normal infants at various ages up to 12 months were studied. All subjects were products of uncomplicated term pregnancies and deliveries and had an unremarkable neonatal course. Infants with undescended testes or hydrocele were excluded. A single observer performed all testicular measurements. The length and breadth of the right testis were measured using a caliber of tuberculin measurement. The volume of the right testis in $\mathrm{ml}$ was obtained using the empirical formula of Lambert (Lambert, 1951), i.e., volume (in $\mathrm{ml})=0.71 \times$ length $\times$ breadth ${ }^{2}$.

Sixty-one samples of saliva from normal male infants, aged from one month to 12 months, were obtained at $1400-1600 \mathrm{~h}$ using a plastic syringe and kept frozen until assay followed by centrifugation to remove debris. An additional 20 samples of saliva from normal adolescents in Tanner's stage P2 to P5 were also obtained as a control. One $\mathrm{ml}$ of saliva was extracted with ether $(5 \mathrm{ml})$ before $\mathrm{T}$ radioimmunoassay (RIA). $\mathrm{T}$ was assayed using the testosterone RIA Kit produced by CIS-Sorin. In order to improve the sensitivity of the assay, the volume of ${ }^{125}$ Itestosterone and antiserum added to the tube was diminished to half the amount descried in the manual of the Kit; i. e., $0.1 \mathrm{ml}$ was diminished to $0.05 \mathrm{ml}$. The accuracy of the modified method was established by adding a known amount of standard $\mathrm{T}(6-50 \mathrm{pg})$ to the salivary pool $(20 \mathrm{pg} /$ tube $)$, and the recovery of added steroid ranged between 70-98\%. The mean recovery of $\mathrm{T}$ was $84 \%$. The precision (intra- and interassay coefficients of variation) at concentrations of between 10-25 pg/tube were less than $16 \%$. With this modified method, the assay sensitivity was $1 \mathrm{ng} / \mathrm{dl}$. Ten of the subjects described above were studied longitudinally by measuring the ST level and crown-heel length from birth to 3-4 months $(n=6)$ and 7 months $(n=4)$.

Regarding the technique of measuring the crown-heel length, birth lengths were obtained by two nurses in the hospital of delivery, and subsequent measurements were made by the same observer with the baby in a supine position facing directly upward and the knees held straight. The details of the measurement technique were the same as described by Steendijk (1966).

The statistical significance between groups determined using Student's $t$-test and the correlation coefficient was computed. The data were reported as mean $\pm \mathrm{SD}$.

\section{Results}

\section{1) Testicular volume}

Mean values and standard deviations for TV in six different periods covering the first year of life are indicated in Fig. 1. Mean TV (ml) increased significantly from birth to one month of age $(P<0.01)$, reaching a peak value at $1-4$ month. The mean TV decreased thereafter, the volume at 6-12 months being significantly less than that at 1-4 months $(\mathrm{P}<0.01)$. There was no significant difference between one month and 3-4 months of age.

\section{2) ST concentration}

Mean values and standard deviations for ST concentrations in five different periods covering the first year of life are also shown in Fig. 1. From 1-4 months, mean ST concentrations increased slowly without significance, reaching a maximum at the age of four months. Thereafter, the decrease in $\mathrm{T}$ was significant as compared to 6-12 months of age (ST, $1-4 \mathrm{M}$ vs $6-12 \mathrm{M}, \mathrm{P}<0.05$ ). On 


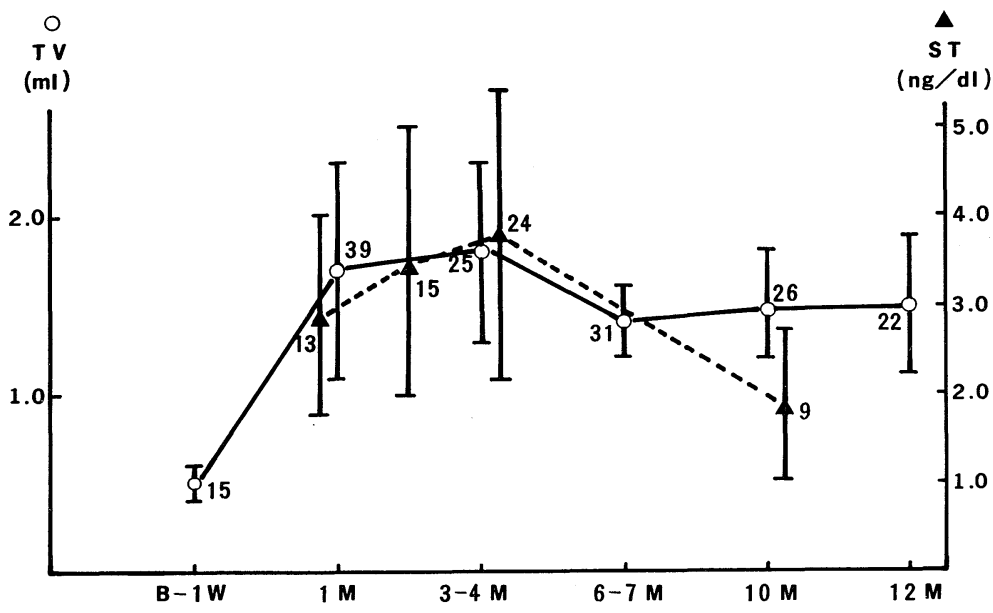

Fig. 1. Salivary testosterone concentrations (ST) (-A $\Delta-)$ and testicular volume (TV) $\left(-\bigcirc-\bigcirc^{-}\right)$in male infants during the first year of life. The results are grouped according to postnatal age $(B, W$ and $M$ mean birth, week and month respectively), as indicated on the bottom of the figure. Each symbol ( $\mathbf{\Delta}$ or $\bigcirc$ ) represents mean $\pm S D$, and the number of samples analyzed in each age group is indicated beside the symbol. the other hand, from one to four months, ST concentrations equaling that of Tanner's pubic hair stage P2-P3 were recognized in 21 of 52 samples, and the mean ST concentration at four months was similar to Tanner's pubic hair stage P2 (3.8 \pm 1.7 vs 5.0 \pm 1.2 ) (Table 1).

\section{3) The relation between $T V$ and $S T$ concen- tration}

There was a positively significant correlation between TV and ST concentrations measured on male infants less than a year old ( $\mathrm{r}=0.567, \mathrm{n}=26, \mathrm{P}<0.01$ ) (Fig. 2).

4) The relation between the fluctuations in monthly height increase $(\triangle H)$ and $S T$ concentrations

During 7 months of observation with four infants, $\triangle H$, determined as the monthly increase in height $(\mathrm{cm} / \mathrm{month})$, varied from $1-6 \mathrm{~cm} /$ month. The ST concentration during this period varied from 1-7 ng/dl (Fig. 3). At 1-4 months of age, $\triangle H$, averaged 3.5 $\mathrm{cm} /$ month, and the ST concentration averaged $3.8 \mathrm{ng} / \mathrm{dl}$. Thereafter, these values decreased to $1.9 \mathrm{~cm} / \mathrm{month}$ and $2.0 \mathrm{ng} / \mathrm{dl}$, respectively, as shown in Fig. 4. In addition, in six infants observed from birth to 3-4 months (Fig. 3), fluctuations in $\triangle \mathrm{H}$ and ST
Table 1. Salivary testosterone concentration in adolescents in various Tanner's pubic hair stages

\begin{tabular}{ccc}
\hline \multicolumn{2}{c}{ Tanner's stage } & Salivary testosterone $(\mathrm{ng} / \mathrm{dl})$ \\
\hline $\mathrm{P}_{2}$ & $\mathrm{n}=5$ & $5.0 \pm 1.2$ \\
$\mathrm{P}_{3}$ & $\mathrm{n}=5$ & $7.7 \pm 2.5$ \\
$\mathrm{P}_{4}$ & $\mathrm{n}=4$ & $13.0 \pm 3.6$ \\
$\mathrm{P}_{5}$ & $\mathrm{n}=6$ & $21.0 \pm 6.0$
\end{tabular}

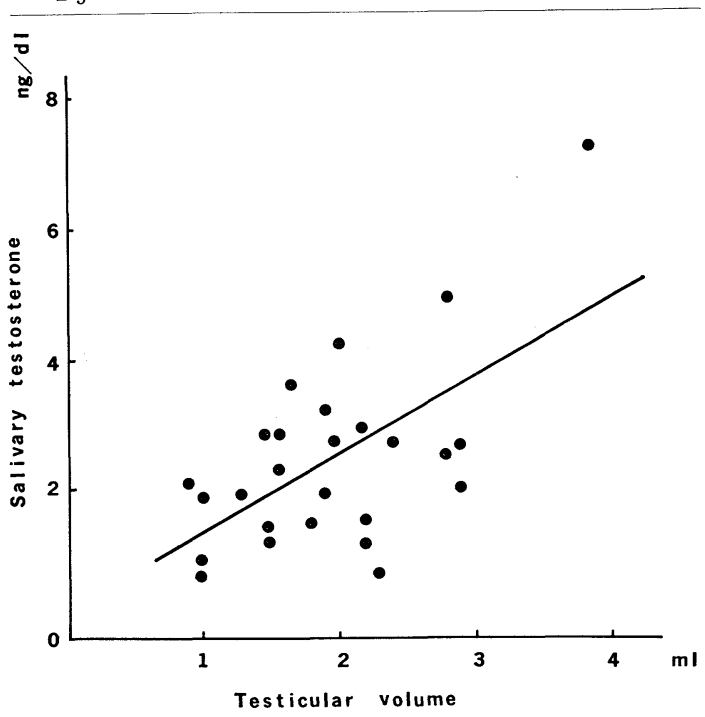

Fig. 2. Comparison of salivary testosterone concentration and testicular volume measured in male infants less than a year old. $n=26$, $\mathrm{r}=0.567, \mathrm{p}<0.01$. 
concentrations seemed to be synchronous.

\section{Discussion}

In 1973, Forest et al. demonstrated a progressive rise in the plasma $\mathrm{T}$ concentration in males after the end of the first postnatal week, with the peak values around the third month, before decreasing to prepubertal values, which are reached at six months.

On the other hand, the age dependency
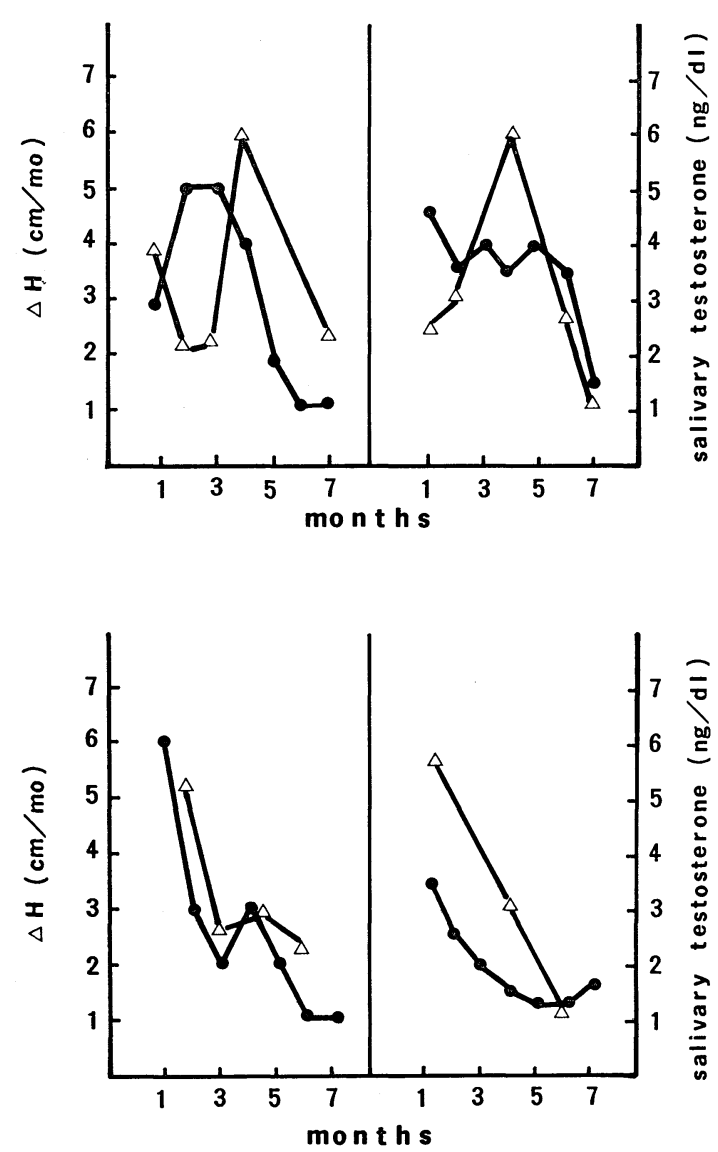

Fig. 3. Monthly $\triangle H$ and ST concentrations for four infants observed for 7 months from birth. $=\triangle H=$ monthly increase in height (cm/month). $\triangle=$ salivary testosterone concentration $(\mathrm{ng} / \mathrm{dl})$. of TeBG in men has been demonstrated by several investigators (Vermeulen et al., 1971 ; Horst et al., 1977). Chaussain et al. (1978) observed the variations in serum TeBG binding capacity in infants during the first year of life, suggesting that the increased $\mathrm{T}$ observed in boys in the first months of life may be a passive phenomenon, secondary to an increase in the serum level of TeBG.

Recently, $\mathrm{T}$ in saliva appear to reflect the non-protein bound $\mathrm{T}$ in the blood and provide useful information about the biologically available androgen without the possible stressful effects of venipuncture and the use of the complicated techniques (Landman et al., 1976; Luisi et al., 1980; Wang et al., 1981; Baxendale et al., 1982). Thus measurement of ST in this period may definetely settle this point.

In addition, the circadian rhythm of the
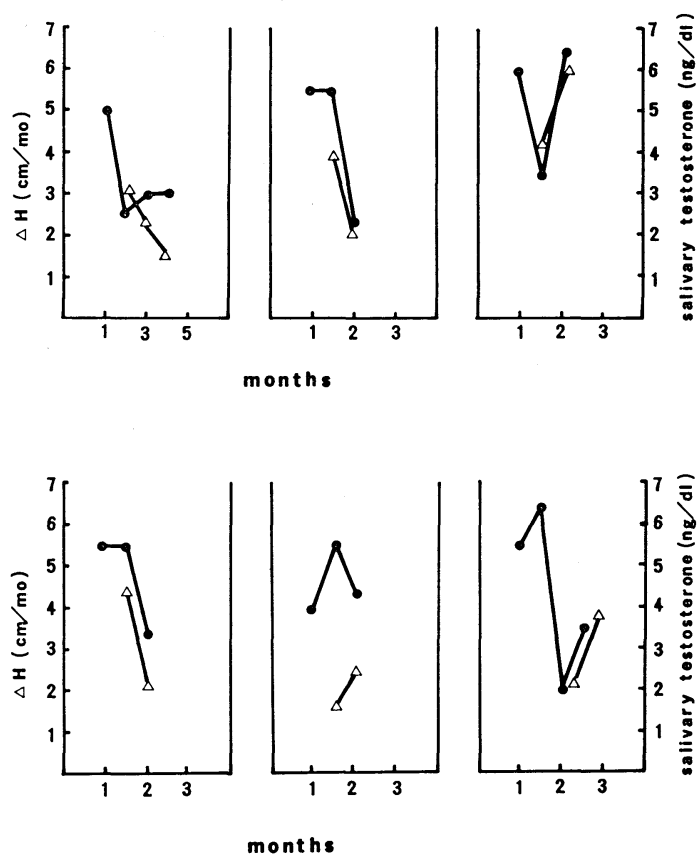

Fig. 4. Monthly $\triangle H$ and ST concentrations for six infants observed for 3-4 months from birth. $=\triangle H=$ monthly increase in height (cm/month). $\triangle=$ salivary testosterone concentrations $(\mathrm{ng} / \mathrm{dl})$. 
ST concentration (Landman et al., 1976) and the inverse relation between the flow rate of parotid fluid and the steroid concentration (Katz and Shannon, 1969), which may affect the accuracy of ST concentration, were reported. Therefore, in this study, all saliva samples were obtained without stimulation at a definite time between 1400 and 1600 $\mathrm{h}$ to obtain accurate information.

Our study shows that the mean ST concentration in male infants reaches its maximum between 1-4 months of age, and the values in 21 out of 52 equal the values in adolescents in Tanner's pubic hair stage P2-P3.

On the other hand, our results on the transient enlargement of the testes and its correlation with ST in early infancy implicate the role of the testes as the source of an androgen surge in the blood. Recently, direct measurement of testicular weight (Bidlingmaier et $a l, 1983$ ) and calculation of germ cells in the testes (Müller and Skakkebaek, 1984) obtained from post mortem male infants in early infancy also showed similar results.

Up to now, studies on age-related variations using either bioassay of sulfate and thymidine incorporation into cartilage or specific radiocompetitive measurement of somatomedins and insulin-like growth factors in human serum have reported low somatomedins in infants (Tato et al., 1975; Foley et al., 1980). The reasons for the remarkable height increase of $16-17 \mathrm{~cm}$ in six manths after birth, which is much more than that of the pubertal growth spurt, have remained unclear.

However, by measuring the growthpromoting activity of plasma, using the lymphocyte assay, Bozzola et al. (1982) suggest that factors other than somatomedins may be active in the early postnatal regulation of growth.

The simultaneous occurrence of a growth spurt and a surge in ST, and synchronous fluctuations of monthly increases in height and ST concentration, as we observed in this study, seem to indicate a close relationship between $\mathrm{T}$ and body height increase in male infants. However, a further investigation, in hypogonadotropic or agonadal male infants, would be necessary to clarify the correlation between $T$ and height increase.

\section{Acknowledgements}

The authors are greatly indebted to Drs. H. Niimi, H. Ushiku and T. Yasuda for their valuable suggestions. This work was supported in part by research grants from the Japanese Ministry of Health and Welfare, and the Growth Science Foundation.

\section{References}

Baxendale, P. M., H. S, Jacobs and V. H. T. James (1982). Salivary testosterone: relationship to unbound plasma testosterone in normal and hyperandrogenic women. Clin. Endocr. 16, 595-603.

Bidlingmaier, F., H. G. Dörr, W. Eisenmenger, U. Kuhnle and D. Knorr (1983). Testosterone and androstenedione concentrations in human testis and epididymis during the first two years of life. J. Clin. Endocrinol. Metab. 57, 311315.

Blizzard, R. M., R. G. Thompson, A. Baghdassarian, A. Kowarski, C. J. Migeon, A. Rodriguez (1974). The interrelationship of steroids, growth hormone and other hormones on pubertal growth. In: Grumbach, M. M., Grave,- G. D., Mayer, E. F. (ed.) The contral of the onset of puberty: 342-359. Wiley Medical, New York.

Bozzola, M., R. M. Schimpff, A. G. Ugazio, G. Thieriot, G. Migrat, L. Nespoli, F. Severi and J. C. Job (1982). Age-related variation in growth-promoting activity of human plasma measured in human lymphocytes. $J$. Clin. Endocrinol. Metab. 55, 40-43.

Cassorla, F. G., S. M. Golden, R. E. Johnsonbaugh, W. M. Heroman, L. Loriaux, R. J. Sherins (1981). Testicular volume during earlp infancy. J. Pediatr. 99, 742-743. 
Chaussain, J. L., A. Brijawi, P. Georges, M. Roger, M. Donnadieu and J. C. Job (1978). Variations of serum testosterone estradiol binding globulins (TeBG) binding capacity in infants during the first year of life... Acta Pediatr. Scand. 67, 649-653.

Esterly, N. B. and L. M. Solomon (1977). Acne neonatrum. In: Schuffer, A. J. and Avery, M.E. (ed.) Disease of the newborn: 973-974. W. B. Saunders, Philadelphia.

Foley, T. P., R. DePhilip, A. Perricelli, A. Miller (1980). Low somatomedine activity in cord serum from infants with intra-uterine growth retardation. J. Pediatr. 96, 605-610.

Forest, M. C., A. M. Cathiard, J. A. Bertrand (1973). Evidence of testicular activity in early infancy. J. Clin. Endocrinol. Metab. 37, 148151.

Garnier, P. E., J. L. Chaussain, E. Binet, A. Schlumberger and J. C. Job (1974). Effect of synthethetic luteinizing hormone-releasing hormone on the release of gonadotropins in children and adolescents: Relations to age, sex and puberty. Acta Endocrinol. 77, 422434.

Gendrel, D., J. L. Chaussain, M. Roger and J. C. Job (1980). Simultaneous postnatal rise of plasma LH and testosterone in male infants. J. Pediatr. 97, 600-602.

Hammond, G. L., M. Koivisto, K. Konuvalainen and R. Vihko (1979). Serum steroids and pituitary hormones in infants with particular reference to testicular activity. J. Clin. Endocrinol. Metab. 49, 40-45.

Horst, H. J., W. Bartsch, I. Dirksen-Thedens (1977). Plasma testosterone, sex hormone binding globulin binding capacity and per cent binding of teststerone and 5- $\alpha$ dihydrotestosterone in prepubertal, pubertal and adult males. J. Clin. Endocrinol. Metab. 45, 522527.

Job, J. C. and R. Francois (1981). Fetus and neonatate. In: Job, J. C. and Pierson, M. (ed.) Pediatric endocrinology : 692-693. Wiley Medical, New York.

Katz, F. H. and I. L. Shannon (1969). Parotid fluid cortisol and cortisone. J. Clin. Invest. 48, 848-857.

Lambert, B. (1951). The frequentry of mumps and mumps orchitis, and the consequences for sexuality and fertility. Acta genet (Basel) 2, suppl. 1 .

Landman, A. D., L. M. Sanford, B. E. Howland, C. Dawes and T. Pritchard (1976). Testosterone in human saliva. Experimentia. 32, 940941.

Luisi, M., G. P. Bernini, D. Genovese, R. Birindelli, D. Barletta, M. Gasperi and F. Franchi (1980). Radioimmunoassay for "free" testosterone in human saliva. J. Steroid. Biochem. 12, 513-516.

Mckiernan, J. F. and D. Hull (1981). Breast development in the newborn. Arch. Dis. Child. 56, 528-528.

Müller, J. and N. E. Skakkebaek (1984). Fluctuations of the number of germ cells during late foetal and early postnatal periods in boys. Acta Endocrinol. 105, 271-274.

Steendijk, R. (1966). Technical aspects of the measurement of length in infants. In: Van Der Werff Ten Bosch, J. J. and Haak, A. (ed.) Somatic growth of the child: 6-9. Stenfert Kroese N. V. Leiden.

Tato, L., M. V. L. Du Caju, C. Pevot, R. Rappaport (1975). Early variations of plasma somadomedine activity in the newborn. $J$. Clin. Endocrinol. Metab. 40, 534-536.

Vermeulen, A., L. Verdonck, M. Van der Straeten and N. Orie (1969). Capacity of testosterone binding globulin in human plasma and influence of specific binding of testosterone on its metabolic clearance rate. J. Clin. Endocrinol. Metab. 29, 1470-1480.

Waldhauser, F., G. Weißenbacher, H. Frisch and A. Pollak (1981). Pulsatile secretion of gonadotropins in early infancy. Eur. $J$. Pediatr. 137, 71-74.

Wang, C., S. Plymate, E. Nieschlag and A. Paulsen (1981). Salivary testosterone in men: Further evidence of a direct correlation with free serum testosterone. J. Clin. Endocrinol. Metab. 53, 1021-1029.

Winter, J. S. D., C. Faiman, W.C. Hodson, A. V. Prasad and F. I. Reyes (1975). Pituitary gonadal relations in infancy. I. : Pattern of serum gonadotropin concentrations from birth to four years of age in human and chimpanzee. J. Clin. Endocrinol. Metab. 40, 545-551.

Zilka, E. and Z. Laron (1969). The normal testicular volume in Israeli children and adolescents. Harefuah. 77, 511-513. 